g,PXYM

Gurual Profesi Kesehatan Masyarakat

http://jurnal.bhmm.ac.id/index.php/jpkm

${ }^{\circledR}$ Corresponding Author.

email address : gilangmhndr388@student.esaunggul.ac.id

Received : 13 Juli 2021 Revised : 17 Agustus 2021 Accepted : 10 Oktober 2021

\title{
Sistem Informasi Peminjaman dan Pengembalian Rekam Medis di Fasilitas Pelayanan Kesehatan (Literature Review)
}

\author{
${ }^{\square}$ Gilang Dasa Dwi Mahendra, Nanda Aula Rumana, Daniel Happy Putra, \\ Laela Indawati \\ Universitas Esa Unggul, Indonesia
}

\begin{abstract}
ABSTRAK
Rekam medis rawat inap harus dikembalikan dalam waktu 2 x24 sedangkan 1x24 jam untuk rekam medis rawat jalan setelah pasien pulang. Buku ekspedisi rekam medis merupakan buku bukti adanya transaksi/ erah terima berkas rekam medis untuk keperluan pelayanan kesehatan pasien. Dengan adanya sistem informasi untuk mempermudah petugas dalam pencatatan, peminjaman, pengembalian, mengontrol dan mengendalikan rekam medis. Penelitian ini bertujuan mengetahui bagaimana perancangan sistem infromasi peminjaman dan pengembalian rekam medis, system infromasi yang paling banyak digunakan serta kelebihan dan kekurang sistem informasi tersebut. Penelitian ini merupakan studi literature review dengan menggunakan 9 jurnal. Berdasarkan tinjauan literature review terhadap 9 jurnal terkait perancangan system informasi peminjaman dan pengembalian rekam medis ditemukan 8 jurnal dengan pengembangan sistem SDLC (Software Development Life Cycle) dengan metode 7 Waterfall, dan 1 metode Prototype, sedangakan ditemukan 1 jurnal dengan Unified Modeling Language (UML). Sistem infromasi dengan permodelan waterfall banyak digunakan karena dinilai model ini cocok untuk proyek yang singkat dan tahapannya jelas. Kelebihan dan kekurang sistem diatas beragam sesuai implementasi aplikasi dan penyimpanan basis data yang digunakan.
\end{abstract}

Kata kunci: Peminjaman, Pengembalian, Rekam Medis, Sistem Informasi.

Information System Borrowing and Returning Medical Records in Health Care Facilities (Literature Review)

\begin{abstract}
Inpatient medical records must be returned within $2 \times 24$ while $1 \times 24$ hours for outpatient medical records after the patient returns home. The medical record expedition book is a proof of the existence of a transaction/ handover of medical record files for the purposes of patient health services. With the information system to facilitate officers in recording, borrowing, returning, controlling and controlling medical records. This study aims to determine how to design an information system for borrowing and returning medical records, the most widely used information system and the advantages and disadvantages of the information system. This research is astudy literature review using 9 journals. Based on a literature review of 9 journals related to the design of information systems for borrowing and returning medical records found 8 journals withsystem development SDLC (Software Development Life Cycle) with 7method Waterfall, and 1method Prototype, while 1 journal with Unified Modeling Language (UML) was found. The information system with the waterfall model is widely used because it is considered that this model is suitable for short projects and clear stages. The advantages and disadvantages of the above system vary according to the application implementation and database storage used.
\end{abstract}

Kata kunci: Borrowing, Returning, Medical Records, Information Systems.

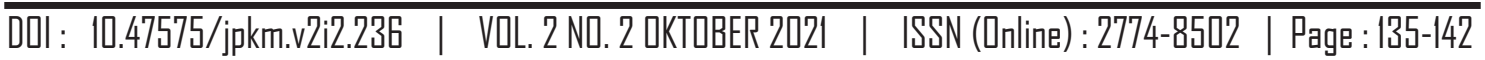




\section{PENDAHULUAN}

Fasilitas pelayanan kesehatan adalah suatu tempatyang digunakanuntukmenyelenggarakan upaya pelayanan kesehatan, baik promotif, preventif, kuratif maupun rehabilitatif yang dilakukan oleh pemerintah, pemerintah daerah dan/atau masyarakat. Sedangkan puskesmas adalah fasilitas pelayanan kesehatan yang menyelenggarakan upaya kesehatan masyarakat dan upaya kesehatan perseorangan tingkat pertama, dengan lebih mengutamakan upaya promotif dan preventif di wilayah kerjanya (Kemenkes, 2019).

Menurut Keputusan Menteri Kesehatan Republik Indonesia No. 340/MENKES/PER/ III/2010 rumah sakit adalah insitusi pelayanan kesehatan yang menyelenggarakan pelayanan kesehatan perorangan secara paripurna yang menyediakan pelayanan rawat inap, rawat jalan, dan gawat darurat (Kemenkes RI, 2010). Menurut WHO (World Health Organization), rumah sakit adalah bagian integral dari suatu organisasi sosial dan kesehatan dengan fungsi menyediakan pelayanan paripurna (komprehensif), penyembuhan penyakit (kuratif) dan pencegahan penyakit (preventif) kepada masyarakat. Rumah sakit juga merupakan pusat pelatihan bagi tenaga kesehatan dan pusat penelitian medik (Organization and Health, 1947).

Berbagai cara dilakukan puskesmas dan rumah sakit untuk menjaga mutu pelayanan kesehatan. Salah satunya dengan menyediakan sistem rekam medis yang baik. Berkas rekam medis memiliki kegunaan sebagai alat komunikasi antara dokter dan tenaga kesehatan lainnya yang ikut ambil bagian dalam memberikan pelayanan. Berdasarkan Peraturan Menteri Kesehatan Republik Indonesia nomor 269/MENKES/PER/III/2008 rekam medis adalah berkas yang berisikan catatan dan dokumen tentang identitas pasien, pemeriksaan, pengobatan, tindakan dan pelayanan lain yang telah diberikan kepada pasien (Kemenkes, 2008). Penerapan sistem informasi akan membuat layanan rekam medis lebih efesien dan efektif. Salah satunya penerapan sistem informasi peminjaman dan pengembalian berkas rekam medis.

Pada umumnya rumah sakit dan puskesmas hanya menggunakan buku eks- pedisi sebagai petunjuk untuk mengetahui dan memonitor rekam medis yang dipinjam dan dikembalikan. prosedur peminjaman rekam medis masih memerlukan waktu yang relatif lama karena harus mencatat nomor urut pasien, nama pasien dan nomor rekam medis pasien dibuku ekspedisi sesuai poliklinik yang dituju. Selain itu ketika buku ekspedisi yang sama dibutuhkan dalam waktu yang sama untuk mencatat peminjaman dan pengembalian sehingga membuat waktu menjadi tidak efektif karena dapat menyebabkan penumpukan berkas yang akan dikembalikan dan waktu yang lama untuk dikirim ke poliklinik yang dituju, kemudian bon peminjaman masih dilakukan dengan cara pencatatan (Susanti, 2014). Oleh sebab itu diperlukan sistem informasi yang dapat mengatur data peminjaman dan pengembalian berkas rekam medis.

Berdasarkan hasil penelitian lain yang dilakukan di Rumah Sakit Wijaya Kusuma Lumajang masih mengalami keterlambatan pengembalian. Hal tersebut disebabkan oleh faktor tidak adanya buku ekspedisi berkas rawat jalan, faktor petugas tidak membuat tracer saat proses peminjaman rekam medis, dan faktor petugas yang lupa dengan tanggal pengembalian rekam medis (Widyastuti et al., 2020).

Dalam Pedoman Penyelenggaraan Rekam Medis dan Informasi Kesehatan di Rumah Sakit (2010) standar pelayanan minimal bahwa rekam medis rawat inap harus dikembalikan dalam waktu 2x24 dan 1x24 jam untuk rekam medis rawat jalan setelah pasien pulang. Hal ini dapat mengganggu penyediaan berkas rekam medis secara cepat dan tepat. Berkas rekam medis yang belum kembali dan keberadaannya tidak tercatat maka untuk mempercepat pelayanan petugas pendaftaran membuat rekam medis rawat jalan baru. Sehingga dokter mengalami kesulitan dalam memeriksa pasien sebab catatan perawatan sebelumnya tidak tercantum dalam berkas rekam medis pasien (Kemenkes, 2006).

Berdasarkan hasil penelitian lain menunjukkan bahwa waktu pengembalian berkas rekam medis yang tepat waktu sebanyak 57 berkas rekam medis atau 29\%, sedangkan waktu pengembalian berkas rekam medik yang tidak tepat waktu sebanyak 138 berkas 
atau 71\% (Winarti and Supriyanto, 2013). Hasil penelitian lain yang dilakukan di rumah sakit An-Nisa Tanggerang waktu pengembalian rekam medis ke Instalasi rekam medis, prosentase pengembalian rekam medis yang $\leq 1 \times 24$ jam sebesar $83 \%$ dan yang $>1 \times 24$ jam sebesar 17\% (Muchtar and Yulia, 2017). Keterlambatan pengembalian pada rekam medis dapat mempersulit petugas dalam mengontrol peminjaman dan pengembalian berkas rekam medis (Anggreini, 2018).

Sistem informasi dibuat didasari permasalahan pencatatan penyelenggaraan peminjaman, pengembalian berkas rekam medis. Sistem informasi ini terkomputerisasi dimana dalam melakukan peminjaman dan pengembalian rekam medis tidak manual lagi. Tujuan sistem informasi ini untuk mempermudah petugas dalam pencatatan, peminjaman, pengembalian, mengontrol dan mengendalikan rekam medis. Peminjaman dan pengembalian rekam medis harus dikendalikan dan dikontrol dengan baik untuk mengurangi kehilangan dokumen rekam medik dan terjadinya miss file (Zuhro et al., 2020).

Sistem rekam medis secara komputerisasi dapat mengurangi kesalahan pada manusia (human error) dalam melakukan pekerjaannya dan dapat meningkatkan kualitas pelayanan yang diberikan kepada setiap pasien yang berobat. Oleh karena itu, penggunaan sistem informasi yang berbasis komputerisasi di suatu rumah sakit sangat penting dalam melaksanakan kegiatan pelayanan terhadap pasien (Gunarti, Rosyadi and Abdurrahman, 2018).

Dampak dari digunakannya sistem informasi peminjaman dan pengembalian berkas rekam medis membantu memperlancar kegiatan pencatatan keluar masuknya berkas rekam medis rawat jalan, rawat inap, gawat darurat, dan keperluan penelitian sehingga dapat selalu terkontrol dan meminimalisir resiko terhadap kesulitan pencarian berkas rekam medis. Sistem peminjaman dan pengembalian rekam medis dapat disempurnakan dengan mengimplementasikan pada teknologi komputer, dengan merancang sistem informasi yang saling terintegrasi (Hikmah, Farlinda and Kurniawan, 2015).

Sehingga tujuan penelitian ini: Mengetahui perancangan sistem informasi peminjaman dan pengembalian rekam medis di fasilitas pelayanan kesehatan, Mengetahui kelebihan dan kekurangan sistem informasi peminjaman dan pengembalian rekam medis di fasilitas pelayanan kesehatan.

\section{METODE PENELITIAN}

Penelitian ini menggunakan metode kajian literature review/tinjauan literatur adalah tinjauan komprehensif dari penelitian sebelumnya tentang topik sistem infromasi peminjaman dan pengembalian rekam medis di fasilitas pelayanan keseatan. Pencarian literature menggunakan data base Google Scholar dengan startegi pencarian jurnal "Sistem Informasi AND Peminjaman OR Pengembalian AND Berkas Rekam Medis". Dari pencarian literature dengan kata kunci "Sistem Informasi AND Peminjaman OR Pengembalian AND Berkas Rekam Medis" ditemukan data 761 setelah dicari menggunakan kriteria inkulis dan eksklusi sampel pada penelitian ini didapatkan 9 jurnal.

Kriteria inklusi untuk menilai jurnal yang akan dipilih dalam penelitian ini yaitu jurnal yang membahas mengenai perancangan sistem informasi peminjaman dan pengembalian rekam medis dengan rentang waktu 20102020, tempat penelitiannya di rumah sakit dan puskesmas, dan jurnal yang digunakan bahasa indonesia. Kriteria eksklusi untuk menilai jurnal yang akan dipilih dalam penelitian ini yaitu Abstrak tidak terstruktur, tujuan tidak relevan, metode tidak jelas, jurnal tidak dapat didownload, dan jurnal hanya tersedia abstrak, bukan full text.

\section{HASIL DAN PEMBAHASAN}

Perancangan Sistem Informasi Peminjaman dan Pengembalian Rekam Medis di Fasilitas Pelayanan Kesehatan

Berdasarkan penelitian literature review yang dilakukan terhadap 9 jurnal tentang sistem informasi peminjaman dan pengembalian rekam medis di rumah sakit.

Berdasarkan tabel 1 ditemukan dari 9 jurnal yang digunakan 8 jurnal dengan pengembangan sistem SDLC (Software Development Life Cycle) 7 dengan metode waterfall dan 1 dengan metode prototype dan 1 jurnal dengan UML (Unified Modelling Language). 
Tabel 1

Metode Perancangan Sistem Informasi Peminjaman dan Pengembalian Rekam Medis di Fasilitas Pelayanan Kesehatan

\begin{tabular}{lll}
\hline No & Hasil & No Referensi \\
\hline 1 & $\begin{array}{l}\text { SDLC (Software Development Life } \\
\text { Cycle) dengan metode Waterfall }\end{array}$ & (Hikmah, Farlinda and Kurniawan, 2015), \\
& & (Anggreini, 2018), (Jamil, Farlinda and Deharja, \\
& & $\begin{array}{l}\text { 2020), (Zuhro et al., 2020), (Gunarti, Rosyadi } \\
\text { and Abdurrahman, 2018), (Jamil et al., 2020), } \\
\end{array}$ \\
& & (Apriliani et al., 2020) \\
2 & $\begin{array}{l}\text { SDLC (Software Development Life } \\
\text { Cycle) dengan metode prototype }\end{array}$ & (Widyastuti et al., 2020) \\
3 & UML (Unified Modelling Language) & (Susanti, 2014)
\end{tabular}

Sumber: Data Diolah, 2021

Kelebihan dan Kekurangan Sistem Informasi Peminjaman dan Pengembalian Rekam Medis di Fasilitas Pelayanan Kesehatan

Berdasarkan tabel 2 sistem yang menggunkan model waterfall tampilan sistemnya userfriendly menu pilihannya juga lengkap sesuai kebutuhan pengguna dan ada nya warning alert yang mengingatkan peminjaman apabila terlambat menggembalikan rekam medis kekurangan sistem ini belum terintgrasi dengan tempat pendaftran. Sedangkan dengan menggunkana model uml UML (Unified Modelling Language) sistem yang dirancang sudah terintegrasi dengan tempat pendaftaran, dan yang menggunkan prototype mendefinisikan sebuah sistem secara berulangulang jadi pengguna langsung mengerti ketika sistem telah selesai.

Metode Perancangan Sistem Informasi Peminjaman dan Pengembalian Rekam Medis di Fasilitas Pelayanan Kesehatan

Berdasarkan perancangan sistem informasi peminjaman dan pengembalian rekam medis di atas rata-rata langkah awalnya membuat analisa kendala sesuai kebutuhan rumah sakit lalu melakukan pengumpulan data bisa menggunakan wawancara maupun observasi kepada petugas rekam medis yang nantinya sebagai pengguna sistem informasi tersebut. Selanjutnya membuat flowchart, context diagram system, data flow diagram dan entity relationship diagram sesuai alur peminjman dan pengembalian rekam medis di rumah sakit tersebut. Dari rancangan entity relationship diagram yang dibuat menggambarkan hubungan relasi sistem informasi peminjaman

dan pengembalian rekam medis. Setelah adanya rancangan $E R D$ maka table tersebut diaplikasikan untuk bahan mendesain tabel database sistem informasi peminjaman dan pengembalian rekam medis. Dari rancangan desain form yang dibuat, digambarkan desain form sesuai dengan alur flowchart, context diagram, data flow diagram, dan entity relationship diagram yang dibuat untuk tampilan sistem informasi peminjaman dan pengembalian rekam medis.

Metode waterfall adalah model proses pertamayang diperkenalkan daripengembangan sistem SDLC. Ini juga disebut sebagai model siklus hidup sekuensial linier. Ini sangat sederhana untuk dipahami dan digunakan. Dalam model waterfall, setiap fase harus diselesaikan sebelum fase berikutnya dapat dimulai dan tidak ada fase yang tumpang tindih. Desain Model Waterfall Pendekatan waterfall adalah Model SDLC pertama yang digunakan secara luas dalam Rekayasa Perangkat Lunak untuk memastikan keberhasilan proyek. Dalam pendekatan "The Waterfall", seluruh proses pengembangan perangkat lunak dibagi menjadi beberapa fase terpisah. Dalam model Waterfall, biasanya, hasil dari satu fase bertindak sebagai input untuk fase berikutnya secara berurutan (Tutorialspoint.com, 2014).

Prototyping merupakan metode pengembangan perangat lunak, yang berupa model fisik kerja sistem dan berfungsi sebagai versi awal dari sistem. Dengan metode prototyping ini akan dihasilkan prototype sistem sebagai perantara pengembang dan pengguna agar dapat berinteraksi dalam proses kegiatan 
pengembangan sistem informasi. Agar proses pembuatan prototype ini berhasil dengan baik adalah dengan mendefinisikan aturanaturan pada tahap awal, yaitu pengembang dan penguna harus satu pemahaman bahwa prototype dibangun untuk mendefinisikan kebutuhan awal (Purnomo, 2017).

Unified Modeling Language (UML) adalah sebuah bahasa yang berdasarkan gambar untuk menvisualisasikan, menspesifikasikan, membangun dan pendokumentasian dari sebuah sistem pengembangan perangkat lunak berbasis Objek. Unified Modeling Language (UML) bukanlah merupakan bahasa pemprograman tetapi modelmodel yang tercipta berhubungan langsung dengan berbagai macam bahasa pemprograman, sehingga memungkinkan melakukan pemetaan (mapping) langsung dari model-model yang dibuat dengan Unified Modeling Language (UML) dengan bahasabahasa pemprograman berorientasi obyek, seperti Java. UML tersusun atas sejumlah elemen grafis membentuk 9 diagram-diagram (Syafitri, 2019).

\section{Sistem Yang Paling Banyak di Gunakan Untuk Peminjaman dan Pengembalian Rekam Medis di Fasilitas Pelayanan Kesehatan}

Berdasarkan 9 penelitian sistem informasi peminjaman dan pengembalian rekam medis diatas didapatkan bahwa sistem yang paling banyak digunakan ialah dengan metode waterfall yaitu sebanyak 7 penelitian. Model pengembangan waterfall bersifat linear dari tahap awal pengembangan system yaitu tahap perencanaan sampai tahap akhir pengembangan system yaitu tahap pemeliharaan. Tahapan berikutnya tidak akan dilaksanakan sebelum tahapan sebelumnya selesai dilaksanakan dan tidak bisa kembali atau mengulang ke tahap sebelumnya (Susanti \& Andriana, 1972).

Tabel 2

Kelebihan dan Kekurangan Sistem Informasi Peminjaman dan Pengembalian Rekam Medis di Fasilitas Pelayanan Kesehatan

\begin{tabular}{|c|c|c|c|c|}
\hline \multirow{2}{*}{ No } & \multirow{2}{*}{$\begin{array}{l}\text { Sistem yang } \\
\text { digunakan }\end{array}$} & \multicolumn{2}{|c|}{ Hasil } & \multirow{2}{*}{ No Referensi } \\
\hline & & Kelebihan & Kekurangan & \\
\hline 1 & $\begin{array}{l}\text { SDLC (Software } \\
\text { Development Life } \\
\text { Cycle) dengan } \\
\text { metode waterfall }\end{array}$ & $\begin{array}{l}\text { Menu yang ada di } \\
\text { sistem informasi ini } \\
\text { userfrendly dan apa yang } \\
\text { dibutuhkan sudah ada } \\
\text { seperti menu peminjaman, } \\
\text { pengembalian, laporan dan } \\
\text { menu data rekam medis. } \\
\text { Adanya sistem warning } \\
\text { alert apabila peminjam } \\
\text { lupa mengembalikan } \\
\text { rekam medis tepat waktu }\end{array}$ & $\begin{array}{l}\text { Sistem informasi ini } \\
\text { belum terintegrasi } \\
\text { dengan sistem yang ada } \\
\text { di tempat pendaftaran } \\
\text { ataupun SIMRS agar } \\
\text { mudah menambahkan } \\
\text { data pasien baru. }\end{array}$ & $\begin{array}{l}\text { (Hikmah, Farlinda } \\
\text { and Kurniawan, } \\
\text { 2015), (Anggreini, } \\
\text { 2018), (Jamil, } \\
\text { Farlinda and } \\
\text { Deharja, 2020), } \\
\text { (Zuhro et al., 2020), } \\
\text { (Gunarti, Rosyadi } \\
\text { and Abdurrahman, } \\
\text { 2018), (Jamil et al., } \\
\text { 2020), (Apriliani et } \\
\text { al., 2020) }\end{array}$ \\
\hline 2 & $\begin{array}{l}\text { SDLC (Software } \\
\text { Development Life } \\
\text { Cycle) dengan } \\
\text { metode prototype }\end{array}$ & $\begin{array}{l}\text { Adanya notif yang } \\
\text { langsung terhubung ke } \\
\text { WhatsApp peminjaman } \\
\text { apabila terlambat me- } \\
\text { ngembalikan. }\end{array}$ & $\begin{array}{l}\text { Sistem ini belum } \\
\text { terintegrasi dengan } \\
\text { aplikasi SIMRS agar } \\
\text { mudah menambahkan } \\
\text { data pasien baru. }\end{array}$ & $\begin{array}{l}\text { (Widyastuti et al., } \\
\text { 2020) }\end{array}$ \\
\hline 3 & $\begin{array}{l}\text { UML (Unified } \\
\text { Modelling } \\
\text { Language) }\end{array}$ & $\begin{array}{l}\text { Sudah terintegrasi dengan } \\
\text { bagian pendaftaran, pilih- } \\
\text { an periode laporan untuk } \\
\text { dicetak lebih varias seperti } \\
\text { tujuan poli, status pasien, } \\
\text { maupun periode tanggal } \\
\text { yang dipilih }\end{array}$ & $\begin{array}{l}\text { Tampilan menu pada } \\
\text { sistem terlalu polos }\end{array}$ & (Susanti, 2014) \\
\hline
\end{tabular}


Waterfall banyak digunakan di fasilitas pelayanan kesehatan karena persyaratan terdokumentasi dengan sangat baik, jelas dan tetap, definisi produk stabil,teknologi dipahami dan tidak dinamis, tidak ada persyaratan yang ambigu, sumber daya yang cukup dengan keahlian yang dibutuhkan tersedia untuk mendukung produk, proyeknya singkat (Tutorialspoint.com, 2014).

Penggunaan Microsoft visual studio untuk membuat dan memperbaiki flowchart sistem, flowchart program dan entity relationship diagram. Selanjutnya power designer untuk membuat dan memperbaiki context diagram dan data flow diagram level 1, xampp bertugas membuat dan memperbaiki data base yang digunakan dan Notepad ++ membuat dan memperbaiki pengkodean syntax program. Lalu untuk tampilan bisa menggunakan Google Chrome.

\section{Kelebihan dan Kekurangan Sistem Informasi Peminjaman dan Pengembalian Rekam Medis di Fasilitas Pelayanan Kesehatan}

Kelebihan sistem yang menggunakan model waterfall user interface sistemnya lebih mudah digunakan, menu-menu sistem juga lengkap apa yang dibutuhkan user semua tersedia. Kekurangannya sistem yang dirancang belum terintegrasi dengan SIMRM ataupun sistem yang ada di tempat pendaftaran.

Sistem waterfall banyak digunakan untuk perancangan sistem informasi karena mempunyai kelebihan sederhana dan mudah dimengerti dan digunakan, mudah dikelola karena modelnya yang kaku-setiap fase memiliki hasil yang spesifik dan proses peninjauan, fase diproses dan diselesaikan satu per satu, bekerja dengan baik untuk proyek yang lebih kecil di mana persyaratan dipahami dengan sangat baik, tahapan yang ditentukan dengan jelas, proses dan hasil didokumentasikan dengan baik. Tetapi juga mempunyai kekurangan model ini tidak cocok untuk proyek jangka panjang yang persyaratannya memiliki resiko perubahan, karena setelah aplikasi ini dalam tahap pengujian, sulit untuk kembali lagi dan mengubah sesuatu yang tidak terdokumentasi dengan baik dalam tahap konsep sebelumnya(Tutorialspoint.com, 2014).
Kelebihan dengan menggunakan model prototype adanya notif yang langsung terhubung ke WhatssApp peminjam apabila terlambat mengembalikan, kekurangannya tidak terhubung dengan SIRS yang ada di rumah sakit. Kelebihan metode Prototype adanya komunikasi yang baik antara pengembang dan pelanggan, pengembangan dapat bekerja lebih baik dalam menentukan kebutuhan pelanggan, lebih menghemat waktu dalam pengembangan system, penerapan menjadi lebih mudah karena pemakai mengetahui apa yang diharapkannya. Sementara kekurangan metode Prototype, Resiko tinggi yaitu untuk masalah-masalah yang tidak terstruktur dengan baik, ada perubahan yang besar dari waktu ke waktu, dan adanya persyaratan data yang tidak menentu, Interaksi pemakai penting. Sistem harus menyediakan dialog on-line antara pelanggan dan komputer, Hubungan pelanggan dengan komputer yang disediakan mungkin tidak mencerminkan teknik perancangan yang baik (Purnomo, 2017).

Kelebihan dengan menggunakan model UML (Unifield modelling language) sistem infromasi ini sudah bisa terintegrasi dengan sistem pendaftaran yang ada di sana. Kelebihan UML dibandingkan dengan bahasa permodelan yang lain antara lain Menyediakan bahasa pemodelan visual yang ekspresif dan siap pakai untuk mengembangkan dan pertukaran modelmodel yang berarti, Menyediakan mekanisme perluasan dan spesialisasi untuk memperluas konsep- konsep inti, Mendukung spesifikasi independen bahasa pemrograman dan proses pengembangan tertentu, Menyediakan basis formal untuk bahasa pemodelan, Memadukan praktek-praktek terbaik di industri perangkat lunak menjadi terminologi dan notasi yang diterima luas, Sedangkan kekurangan UML antara lain UML bukanlah bahasa pemrograman visual, melainkan bahasa pemodelan visual, UML bukan spesifikasi dari tool, tapi spesifikasi bahasa pemodelan (Syafitri, 2019).

\section{SIMPULAN}

Berdasarkan hasil penelitian yang di-lakukan dengan literature review dengan 10 jurnal perancangan sistem informasi pemijaman dan pengembalian rekam medis di fasilitas pelayanan kesehatan dapat disimpulkan sebagai 
berikut: Pada perancangan sistem informasi peminjaman dan pengembalian rekam medis ditemukan dengan 3 permodelan, dari 9 jurnal ditemukan 7 dengan model waterfall, 1 dengan model UML (Unifield modelling language), 1 penelitian dengan model prototype. Sistem yang paling banyak digunakan adalah dengan permodelan waterfall, yang membedakan waterfall satu dengan yang lain hanya di impelemtasi aplikasi yang digunakan dan data base yang digunakan, Setiap sistem yang menggunkan model waterfall tampilan sistemnya userfriendly menu pilihannya juga lengkap sesuai kebutuhan pengguna dan ada nya warning alert kekurangan sistem ini belum terintgrasi dengan tempat pendaftran. Sedangkan dengan menggunkana model $U M L$ (Unified Modelling Language) sistem yang dirancang sudah terintegrasi dengan tempat pendaftaran, dan yang menggunkan prototype mendefinisikan sebuah sistem secara berulangulang jadi pengguna langsung mengerti ketika sistem telah selesai.

\section{DAFTAR PUSTAKA}

Anggreini, R. D. (2018). Perancangan dan Pembuatan Sistem Informasi Peminjaman dan Pengembalian Berkas Rekam Medis di Rumah Sakit Baladhika Husada Jember. pp. 63-68.

Apriliani, E. D. et al. (2020). Sistem Informasi Peminjaman dan Pengembalian

Rekam Medis Berbasis Sms Gateway', 1(3), pp. 288-296.

Gunarti, R., Rosyadi, M. D. and Abdurrahman. (2018). Perancangan Aplikasi Monitoring Peminjaman Rekam Medis (Retrieval) di RSUD Dr. H. Andi Abdurrahman Noor Kabupaten Tanah Bumbu. pp. 166-171.

Hikmah, F., Farlinda, S. and Kurniawan, M. ari. (2015). Sistem Informasi Sistem Informasi Peminjaman dan Pengembalian Berkas Rekam Medis Rumah Sakit Umum Daerah dr.Soebandi Jember. (269), pp. 189-195.
Jamil, N. M. et al. (2020). Sistem Informasi Peminjaman Dan Pengembalian Dokumen Rekam Medis Menggunakan Metode Waterfall (Studi Kasus Puskesmas. J-REMI: Jurnal Rekam Medik Dan Informasi Kesehatan, 1(2), pp. 94-103.

Jamil, N. M., Farlinda, S. and Deharja, A. (2020). Perancangan dan Pembuatan Sistem Informasi Peminjaman dan Pengembalian Dokumen Rekam Medis Rawat Jalan di RSD Mangusada Badung. 1(3), pp. 288-296.

Kemenkes. (2006). Pedoman Penyelenggaraan Rekam Medis RS 2 CKHVAx. p. 22.

Kemenkes (2008) 'Peraturan Menteri Kesehatan Republik Indonesia Nomor. 269/Menkes/Per/III/2008. Permenkes Ri No 269/Menkes/Per/Iii/2008, p. 7.

Kemenkes (2019) 'Peraturan Menteri Kesehatan RINo 43 tahun 2019', Peraturan Menteri Kesehatan RI No 43 tahun 2019 tentang Puskesmas, Nomor 65(879), pp. 20042006.

Kemenkes RI. (2010). Peraturan Menteri Kesehatan Republik Indonesia Nomor. 340/Menkes/Per/III/2010. p. 116.

Muchtar, R. D. and Yulia, N. (2017). Tinjauan Pengembalian Rekam Medis Rawat Jalan dan Kecepatan Pendistribusian Rekam Medis Ke Poliklinik Di Rumah Sakit an-Nisa Tangerang. Inohim, 5(1), pp. 109-113.

Organization and Health, W. (1947). Definisi Rumah Sakit, www.who.int. Available at: https://www.who.int/. (Accessed: 24 November 2020).

Purnomo, D. (2017) 'Model Prototyping Pada Pengembangan Sistem Informasi. Jurnal Informatika Merdeka Pasuruan, 2(2), 54-61. doi:10.37438/jimp.v2i2.67. 
Susanti, A. S. (2014). Perancangan Sistem Informasi Peminjaman Dan Pengembalian Rekam Medis Guna Menunjang Efektivitas Pelayanan Rekam Medis Di Rsud Kota Bandung. Journal of Chemical Information and Modeling, 53(9), pp. 1689-1699.

Susantu, R. and Andriana, A. D. (1972). Perbandingan Model Waterfall Dan Prototyping Untuk Pengembangan Sistem Informasi. Therapie der Gegenwart, 111(5), pp. 756-757 passim.

Syafitri, Y. (2019). Analisa dan Perancangan Berbasis UML pada Sistem Infromasi Simpan Pinjam Koperasi Swamitra Bandar Lampung. pp. 22-31.

Tutorialspoint.com. (2014). Software Development Life Cycle (SDLC)', Software Development Life Cycle (SDLC), 1(1), pp. 9-12. Available at: http://www. tutorialspoint.com/sdlc/sdlc_tutorial. pdf.
Widyastuti, H. N. et al. (2020). Sistem Informasi Peminjaman Dan Pengembalianrekam Medis Dengan Barcode Dan Notifikasi Whatsapp Di Rumah Sakit Wijaya Kusuma Lumajang. J-REMI Jurnal Rekam Medik dan Informasi Kesehatan, 1(2), pp. 61-76.

Winarti and Supriyanto, S. (2013). Analisis Kelengkapan Pengisian Dan Pengembalian Rekam Medis Rawat Inap Rumah Sakit. Jurnal Administrasi Kesehatan Indonesia, 1(c), pp. 2-6.

Zuhro, L. N. F. et al. (2020). Perancangan Sistem Informasi Peminjaman Dan Pengembalian Brm Rawat Jalan Di Rumah Sakit Husada Utama. Jurnal Rekam Medik Dan Informasi Kesehatan, 1(3), pp. 288-296. 